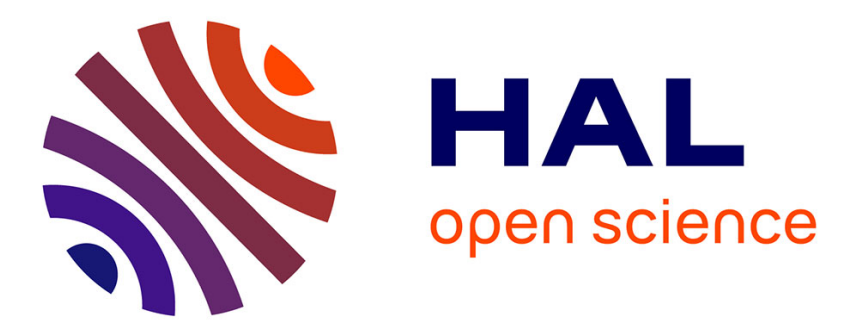

\title{
The open circuit potential of Geobacter sulfurreducens bioanodes depends on the electrochemical adaptation of the strain
}

Laurence Soussan, Benjamin Erable, Marie-Line Délia-Dupuy, Alain Bergel

\section{- To cite this version:}

Laurence Soussan, Benjamin Erable, Marie-Line Délia-Dupuy, Alain Bergel. The open circuit potential of Geobacter sulfurreducens bioanodes depends on the electrochemical adaptation of the strain. Electrochemistry Communications, 2013, vol. 33, pp. 35-38. 10.1016/j.elecom.2013.04.013 . hal00860257

\section{HAL Id: hal-00860257 https://hal.science/hal-00860257}

Submitted on 10 Sep 2013

HAL is a multi-disciplinary open access archive for the deposit and dissemination of scientific research documents, whether they are published or not. The documents may come from teaching and research institutions in France or abroad, or from public or private research centers.
L'archive ouverte pluridisciplinaire HAL, est destinée au dépôt et à la diffusion de documents scientifiques de niveau recherche, publiés ou non, émanant des établissements d'enseignement et de recherche français ou étrangers, des laboratoires publics ou privés. 


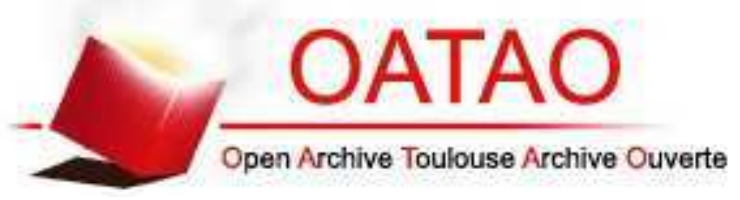

\section{Open Archive TOULOUSE Archive Ouverte (OATAO)}

OATAO is an open access repository that collects the work of Toulouse researchers and makes it freely available over the web where possible.

This is an author-deposited version published in : http://oatao.univ-toulouse.fr/ Eprints ID : 9069

To link to this article : DOI:10.1016/j.elecom.2013.04.013

URL : http://dx.doi.org/10.1016/j.elecom.2013.04.013

To cite this version : Soussan, Laurence and Erable, Benjamin and Délia, Marie-Line and Bergel, Alain. The open circuit potential of Geobacter sulfurreducens bioanodes depends on the electrochemical adaptation of the strain. (2013). Electrochemistry Communications, vol. 33 . pp. 35-38. ISSN $1388-2481$

Any correspondance concerning this service should be sent to the repository administrator: staff-oatao@ listes-diff.inp-toulouse.fr 


\title{
The open circuit potential of Geobacter sulfurreducens bioanodes depends on the electrochemical adaptation of the strain
}

\author{
Laurence Soussan ${ }^{*}$, Benjamin Erable ${ }^{1}$, Marie-Line Delia ${ }^{1}$, Alain Bergel ${ }^{1}$ \\ Laboratoire de Génie Chimique (LGC), CNRS-Université de Toulouse, 4 Allée Emile Monso, BP 84234, 31432 Toulouse, France
}

Keywords:

Geobacter sulfurreducens

Microbial anode

Polarization potential

OCP

Steady state current

Electrocatalytic properties

\begin{abstract}
A B S T R A C T
Bioanodes for acetate oxidation were formed with pure cultures of Geobacter sulfurreducens under constant polarization potential. With the original commercial strain, the bioanodes formed at $+0.2 \mathrm{~V} / \mathrm{SCE}$ exhibited open circuit potential (OCP) of $0.0 \mathrm{~V} / \mathrm{SCE}$, while the bioanodes formed at $-0.2 \mathrm{~V} / \mathrm{SCE}$ had OCP around $-0.52 \mathrm{~V} / \mathrm{SCE}$. In contrast, the bioanodes formed with bacterial cells collected from a previous current-producing bioanode exhibited OCP of $-0.52 \mathrm{~V} / \mathrm{SCE}$ whatever the polarization potential used to form them ( $+0.2 \mathrm{~V} / \mathrm{SCE}$ or $-0.2 \mathrm{~V} / \mathrm{SCE}$ ). The "electrochemically-adapted strain" kept its electrochemical characteristics after successive cultures in solution. High steady-state currents were reached $\left(16-19 \mathrm{~A} \mathrm{~m}^{-2}\right.$ ) in all cases without any dependence on strain adaptation or applied potential.
\end{abstract}

\section{Introduction}

Microbial anodes have known spectacular advances since 10 years from both practical and fundamental aspects [1]. The key concept of microbial anodes is the ability of some bacteria to oxidise organic compounds by transferring the electrons directly to a solid anode. A lot of various bacteria have shown able to catalyse extracellular electron transfer to anodes [2] out of them Geobacter sulfurreducens seems to be the most used for fundamental investigations. A survey of the works devoted to G. sulfurreducens-anodes evidences a wide diversity in electrochemical performances although experimental procedures were rather close: the oxidation of acetate was always used as model reaction, on graphite or carbon electrodes under a constant applied potential. Almost identical maximum current densities of $0.8-1.2 \mathrm{~A} \mathrm{~m}^{-2}$ have been reproduced, even recently, by at least three different groups [3-5]. In contrast, other studies have reported current densities of several $\mathrm{A} \mathrm{m}^{-2}$ [6-8]. High current densities may be explained by an adequate anode structure in some cases [9], but high current densities have also been obtained on flat anodes $[6,8]$. The potential value used to grown the $G$. sulfurreducens cells on the anode has a strong effect on the expression of the compounds that achieve the extracellular electron transfer $[10,11]$, but the effect on the resulting steady-state current is not well established. In some cases, the steady-state current increased with the applied potential until a threshold value ranging from -0.25 to $0.0 \mathrm{~V}$ vs. $\mathrm{Ag} / \mathrm{AgCl}$, while it

\footnotetext{
* Corresponding author. Tel./fax: + 33534323673.

E-mail address: Laurence.Soussan@enscm.fr (L. Soussan).

1 Tel./fax: + 33534323673 .
}

did no longer depend on the applied potential above this threshold $[11,12]$. In other studies, the steady-state current continuously increased over the whole range of applied potentials up to $0.4 \mathrm{~V} \mathrm{vs}$. $\mathrm{Ag} / \mathrm{AgCl}$ [4].

Most cyclic voltammetry curves (CV) indicated open circuit potentials $(\mathrm{OCP})$ ranging from -0.55 to $-0.45 \mathrm{~V}$ vs. $\mathrm{Ag} / \mathrm{AgCl}$ whatever the applied potential. In contrast, biofilms grown at $+0.2 \mathrm{~V} \mathrm{vs}$. $\mathrm{Ag} / \mathrm{AgCl}$ in our previously reported work started to catalyse acetate oxidation only above $0.0 \mathrm{~V}$ vs. $\mathrm{Ag} / \mathrm{AgCl}$ [7]. Practically, an increase of around $500 \mathrm{mV}$ of the OCP represents a dramatic loss of effectiveness.

The objective of the present work was to study the effect of the applied potential used to form the G. sulfurreducens bioanodes on their OCP value. Moreover, G. sulfurreducens is sensitive to electrochemical adaptation. Using G. sulfurreducens cells collected from an already current-producing bioanode to form a new bioanode has led to significantly increased current densities [13]. Here, the possible effect of electrochemical adaptation on OCP value was also investigated, with the objective to obtain high current densities associated with as negative as possible OCP.

\section{Materials and methods}

\subsection{Media and growth conditions}

G. sulfurreducens (ATCC 51573) was purchased from DSMZ. The growth medium contained per litre: $0.1 \mathrm{~g} \mathrm{KCl}, 1.5 \mathrm{~g} \mathrm{NH}_{4} \mathrm{Cl}, 2.5 \mathrm{~g}$ $\mathrm{NaHCO}_{3}, 0.6 \mathrm{~g} \mathrm{NaH}_{2} \mathrm{PO}_{4}, 0.82 \mathrm{~g}$ sodium acetate, $8 \mathrm{~g}$ sodium fumarate, $10 \mathrm{~mL}$ Wolfe's vitamin solution (ATCC MD-VS) and $10 \mathrm{~mL}$ modified Wolfe's minerals (ATCC MD-TMS). The medium without sodium fumarate, vitamins and minerals was first sterilised in bottles. After 
sterilisation, the medium was completed with vitamins, minerals and with a filtered $(0.2 \mu \mathrm{m})$ stock solution of sodium fumarate. For each inoculation, the strain was preliminary sub-cultured in a fresh deoxygenated culture medium $\left(10 \% \mathrm{v} / \mathrm{v}, 30{ }^{\circ} \mathrm{C}\right)$ to reach a final absorbance of 0.4 at $620 \mathrm{~nm}$, then incubated $\left(2 \% \mathrm{v} / \mathrm{v}, 30^{\circ} \mathrm{C}\right)$ in a fresh deoxygenated culture medium for 4 days to obtain a final absorbance around 0.4 at $620 \mathrm{~nm}$.

The medium used in the electrochemical reactors contained per litre: $0.38 \mathrm{~g} \mathrm{KCl}, 0.36 \mathrm{~g} \mathrm{NaCl}, 0.20 \mathrm{~g} \mathrm{NH}_{4} \mathrm{Cl}, 1.80 \mathrm{~g} \mathrm{NaHCO}_{3}, 1.36 \mathrm{~g}$ $\mathrm{Na}_{2} \mathrm{CO}_{3} \cdot 10 \mathrm{H}_{2} \mathrm{O}, 0.22 \mathrm{~g} \mathrm{~K}_{2} \mathrm{HPO}_{4}, 0.42 \mathrm{~g} \mathrm{KH}_{2} \mathrm{PO}_{4}, 1.24 \mathrm{~g}$ sodium acetate, Wolfe's vitamin and minerals (identical as growth medium). In the reactor medium, acetate $15 \mathrm{mM}$ was the sole electron donor and no fumarate was present.

\subsection{Electrodes and reactors}

Electrochemical reactors containing $0.45 \mathrm{~L}$ medium were used with a single working electrode, while reactors with $1.8 \mathrm{~L}$ medium were implemented with two working electrodes. These reactors were made of glass and the headspace volume was about $20 \%$ of the total volume. The top of the reactors comprised sampling ports and the junction between the top and the body of reactor was sealed with a clamping ring. Sampling ports were sealed with butyl stoppers. Auxiliary electrodes were platinum grids (Platecxis) cleaned by means of red-hot heating flame. Potentials were controlled and expressed versus saturated calomel electrodes (SCE, potential $0.241 \mathrm{~V} / \mathrm{SHE}$, Radiometer analytical), the potential of which was checked at the beginning and the end of each experiment. Working electrodes were $2.5 \mathrm{~cm} \times 1.0 \mathrm{~cm} \times 0.5 \mathrm{~cm}$ graphite coupons (Goodfellow) electrically connected with titanium wires shielded with thermoretractable sheaths. Before each experiment, graphite electrodes were cleaned for $1 \mathrm{~h}$ in $1 \mathrm{~N} \mathrm{HCl}$ to dissolve adsorbed organic species and $1 \mathrm{~N} \mathrm{NaOH}$ to neutralize acidity and finally rinsed with sterilised ultrapure water.

\subsection{Experiments}

Potentials were applied with a multi-channel potentiostat (VMP Biologic SA) using a N-STAT device when several working electrodes were individually addressed in the same reactor, and currents were recorded every $900 \mathrm{~s}$. Chronoamperometries were suspended periodically to record cyclic voltammetry (CV) at $1 \mathrm{mV} \mathrm{s}^{-1}$ from -0.6 to $0.5 \mathrm{~V} / \mathrm{SCE}$. Reactors were filled with the medium, flushed with $\mathrm{N}_{2}-\mathrm{CO}_{2}$ $(80 \%-20 \%)$ and polarized for $12 \mathrm{~h}$ before bacteria cell inoculation $(10 \% \mathrm{v} / \mathrm{v})$.

Biofilm sampling was performed in aseptic conditions. Biofilms were scrapped off the anode under anaerobic conditions, transferred into a deoxygenated fresh growth medium and incubated 3 days at $30{ }^{\circ} \mathrm{C}$ until the absorbance at $620 \mathrm{~nm}$ reached 0.3 . This strain was called the "electrochemically-adapted strain".

Four reactors (I, II, III and IV) were operated. Reactors I and II were inoculated with the original DSMZ strain that had never been used before for electrochemical experiments and the working electrodes were polarized at +0.2 and $-0.2 \mathrm{~V} / \mathrm{SCE}$ for reactors I and II, respectively. Reactors III and IV were inoculated with the "electrochemically-adapted strain". Reactor III contained two working electrodes that were polarized at +0.2 and $-0.2 \mathrm{~V} / \mathrm{SCE}$ respectively. The "electrochemically-adapted strain" was then sub-cultured seven times in solution and finally used to inoculate the Reactor IV whose electrode was polarized at $+0.2 \mathrm{~V} / \mathrm{SCE}$

\section{Results and discussion}

Reactors I and II were inoculated with the original DSMZ strain that had never been used before for electrochemical experiments and the working electrodes were polarized at +0.2 and $-0.2 \mathrm{~V} / \mathrm{SCE}$ for reactors I and II, respectively. The two graphite electrodes polarized at $+0.2 \mathrm{~V} / \mathrm{SCE}$ (Reactor I) exhibited strictly identical evolutions of current versus time (Fig. 1A,I). The current started to increase less than one day after reactor inoculation until reaching a maximum around $16 \mathrm{~A} \mathrm{~m}^{-2}$, which remained stable for more than two days. The electrode polarized at $-0.2 \mathrm{~V} / \mathrm{SCE}$ (Reactor II) showed similar current evolution, reaching a maximum around $19 \mathrm{~A} \mathrm{~m}^{-2}$ after 4 days and being stable above $16 \mathrm{~A} \mathrm{~m}^{-2}$ for more than 4 days (Fig. 1A,II). Identical steady-state currents were obtained here with applied potentials of -0.2 and $0.2 \mathrm{~V} / \mathrm{SCE}$. These results were in agreement with some previous studies that did not observe an effect of the applied potential above a threshold value of the order of -0.25 to $0.0 \mathrm{~V} \mathrm{vs.} \mathrm{Ag} / \mathrm{AgCl}$ depending of the authors [11,12].

The control cyclic voltammetry (CV) recorded just before inoculation, i.e. after $12 \mathrm{~h}$ abiotic polarization, showed no current production in any experiment (Fig. 1B). The subsequent CVs always showed a sigmoid shape with a current plateau, as it has commonly been reported for $G$. sulfurreducens-anodes [4,6,8,11]. In reactor I (applied potential $+0.2 \mathrm{~V} / \mathrm{SCE}$ ), CVs recorded when biofilms were 5.9-day old showed acetate oxidation starting around $0 \mathrm{~V} / \mathrm{SCE}$ and reached maximum current around $19 \mathrm{~A} \mathrm{~m}^{-2}$ since around $0.30 \mathrm{~V} / \mathrm{SCE}$ (Fig. 1B,I). CVs recorded in reactor II (applied potential $-0.2 \mathrm{~V} / \mathrm{SCE}$ ) had the same shape but drastically different characteristics, with open circuit potentials around $-0.52 \mathrm{~V} / \mathrm{SCE}$ and maximum currents reached since $-0.25 \mathrm{~V} / \mathrm{SCE}$. Similar CVs shapes were observed during the whole biofilm growth phase (days 1.3, 2.7 and 4.2).

The open circuit potential of $0.0 \mathrm{~V} / \mathrm{SCE}$ observed with the electrodes polarized at $+0.2 \mathrm{~V} / \mathrm{SCE}$ perfectly confirmed our previous study [7], which described anodes that were not able to produce current at potentials lower than $0.0 \mathrm{~V} / \mathrm{SCE}$. In contrast, the $\mathrm{CV}$ s obtained with the electrode polarized at $-0.2 \mathrm{~V} / \mathrm{SCE}$ perfectly fitted CVs reported by several groups with open circuit potentials ranging from -0.55 to $-0.45 \mathrm{~V} / \mathrm{SCE}[8,11]$. It can be noted that current densities recorded here were in both reactors the highest reported so far. For instance, the current density of $6 \mathrm{~A} \mathrm{~m}^{-2}$ produced at $-0.4 \mathrm{~V} / \mathrm{SCE}$ (Fig. 1A,II) is higher than the current density obtained with the most efficient strain reported at similar potential (2.5 $\mathrm{A} \mathrm{m}^{-2}$ at $-0.4 \mathrm{~V}$ vs. $\mathrm{Ag} / \mathrm{AgCl}[13]$ ).

These results demonstrated a drastic influence of the polarization potential on the G. sulfurreducens electrochemical behaviour and particularly on the OCP. G. sulfurreducens was notably able to grow and form efficient bioanodes at $-0.2 \mathrm{~V} / \mathrm{SCE}$, while when grown at $+0.2 \mathrm{~V} / \mathrm{SCE}$ it was not able to produce current at $-0.2 \mathrm{~V} / \mathrm{SCE}$. To the best of our knowledge, such behaviours were described here for the first time.

Yi et al. [13] have demonstrated that a prior adaptation of the G. sulfurreducens strain at $-0.4 \mathrm{~V}$ vs. $\mathrm{Ag} / \mathrm{AgCl}$ for 5 months leads to an enhancement of the steady-state current when the pre-adapted strain was then grown at $-0.4 \mathrm{~V} \mathrm{vs} . \mathrm{Ag} / \mathrm{AgCl}\left(3.5 \mathrm{~A} \mathrm{~m}^{-2}\right.$ for the original strain, $9.7 \mathrm{~A} \mathrm{~m}^{-2}$ for the pre-adapted strain). We therefore investigated the possible enhancement of the electrochemical behaviour of the DSMZ strain induced by a pre-adaption of this strain at $-0.2 \mathrm{~V} / \mathrm{SCE}$. Biofilm formed in reactor II was maintained for one month at $-0.2 \mathrm{~V} / \mathrm{SCE}$ and sampled while the current density was $5 \mathrm{~A} \mathrm{~m}^{-2}$. The biofilm sample was cultivated in solution and then used to inoculate a fresh reactor (Reactor III) that contained two graphite electrodes polarized respectively at +0.2 and $-0.2 \mathrm{~V} / \mathrm{SCE}$.

Current evolutions versus time did not show major difference as a function of the applied potential and were similar to those recorded with the original strain. CVs of the electrode polarized at $-0.2 \mathrm{~V} / \mathrm{SCE}$ were also similar to those recorded with the initial strain grown at the same potential. In contrast, CVs of the electrode polarized at $+0.2 \mathrm{~V}$ exhibited similar shape than those of the electrode polarized at $-0.2 \mathrm{~V}$ (Figs. 1B,II and 2B,III), with the oxidation process starting around $-0.52 \mathrm{~V} / \mathrm{SCE}$ and a plateau reached from $-0.25 \mathrm{~V} / \mathrm{SCE}$. The current generated at $-0.4 \mathrm{~V} / \mathrm{SCE}$ was as high as $7 \mathrm{~A} \mathrm{~m}^{-2}$ (Fig. 2A,III). The "electrochemically-adapted strain" exhibited thus similar high steadystate currents and low OCP of $-0.52 \mathrm{~V} / \mathrm{SCE}$, whatever the polarization potential $(+0.2 \mathrm{~V} / \mathrm{SCE}$ or $-0.2 \mathrm{~V} / \mathrm{SCE})$. In conclusion, the original strain 
A

(Chronoamperometry)

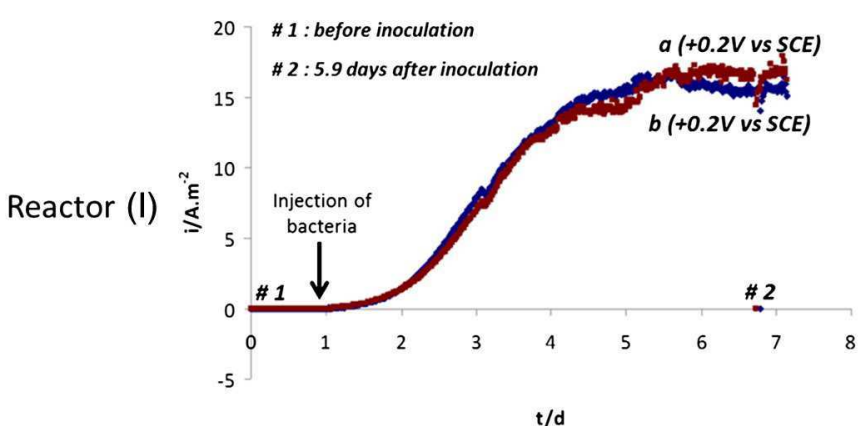

$t / d$

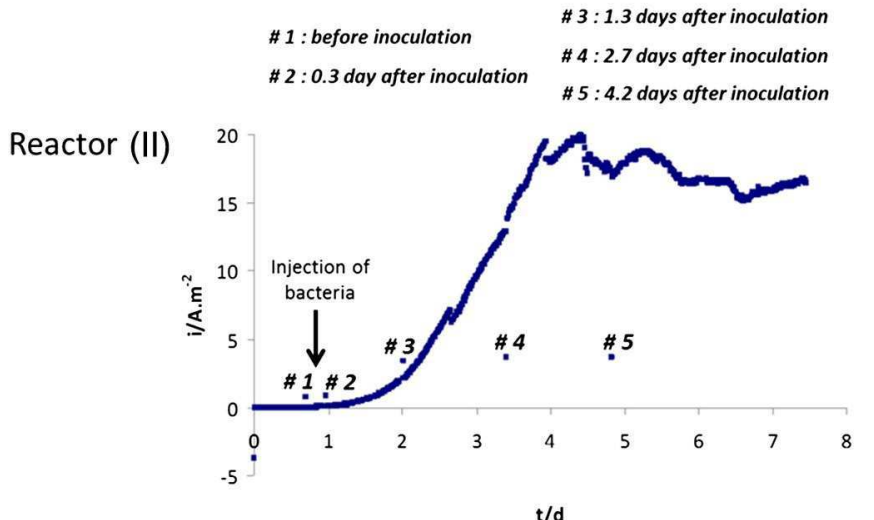

B

(Cyclic voltammetry)
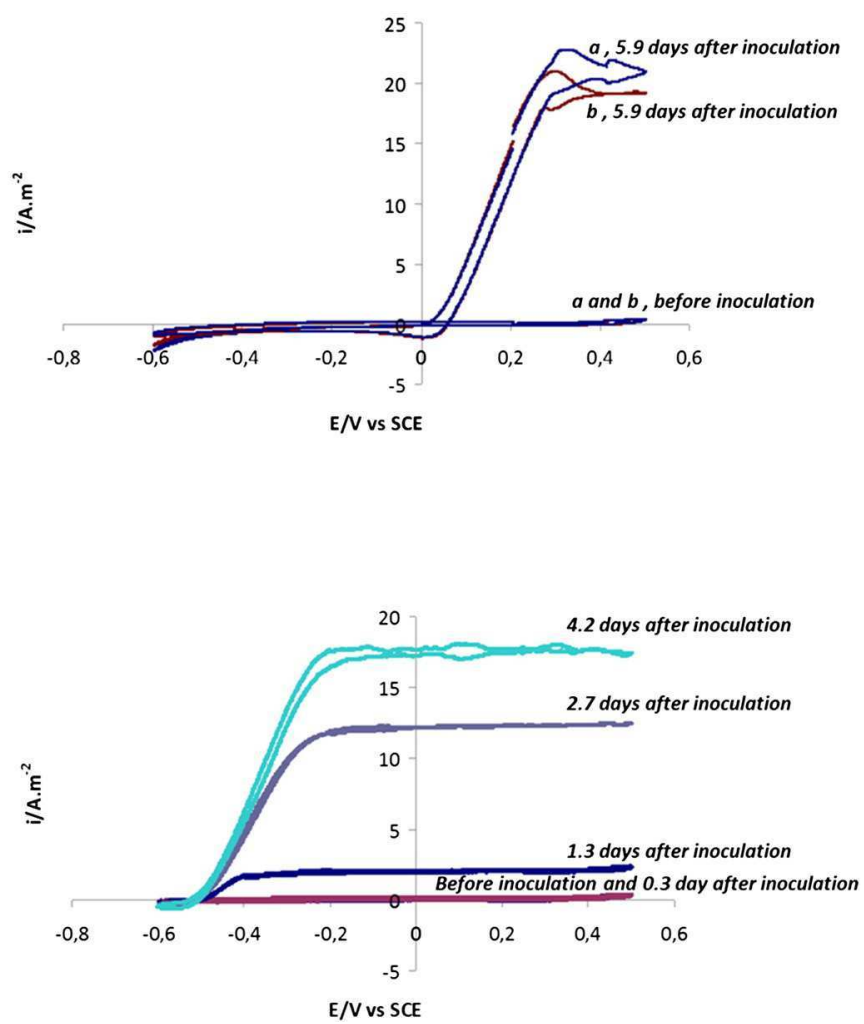

Fig. 1. Bionaodes formed with the original commercial G. sulfurreducens strain. A) Current density versus time (\# indicate the interruptions for CV recording); B) Cyclic voltammetries performed at $1 \mathrm{mV} \mathrm{s}{ }^{-1}$ during chronoamperometry. (I) Reactor with two electrodes polarized at $+0.2 \mathrm{~V} / \mathrm{SCE}$ (a and $\mathrm{b}$ ); CVs on electrodes a and b performed before bacteria injection and 5.9 days after bacteria injection. (II) Reactor with an electrode polarized at $-0.2 \mathrm{~V} / \mathrm{SCE}$; CVs performed before bacteria injection, 0.3 , $1.3,2.7$, and 4.2 days after bacteria injection.

grown at $+0.2 \mathrm{~V} / \mathrm{SCE}$ was not able to develop electrocatalysis at low potentials (below around $0.0 \mathrm{~V} / \mathrm{SCE}$ ), while the "electrochemically-adapted strain" exhibited identical low OCP independently on the applied potential used to grow it. To the best of our knowledge, such an OCP expansion linked to a pre-adaption of the strain was also reported here for the first time.

With the objective to know whether the adapted strain was transitory adapted to electrochemical growth or whether it got permanent characteristics, it was replicated seven times in solution before being used as inoculum with an electrode polarized at $+0.2 \mathrm{~V} / \mathrm{SCE}$ (Reactor IV). Current evolution (Fig. 2A,IV) was identical to those observed for all previous reactors and CVs (Fig. 2B,IV) showed that the strain had kept its efficient electrocatalytic properties with oxidation starting around $-0.52 \mathrm{~V} / \mathrm{SCE}$ and the maximum current density reached from $-0.25 \mathrm{~V} / \mathrm{SCE}$. The "electrochemically-adapted strain" had thus acquired permanent electrocatalytic properties. The maximum steady-state current recorded during chronoamperometry was slightly lower (around $14 \mathrm{~A} \mathrm{~m}^{-2}$ ) than for the previous bioanodes, which may indicate that the electrochemical properties of the strain were, however, a little affected by the seven replications in solution.

\section{Conclusion}

This work confirmed the great ability of G. sulfurreducens to adapt to electrochemical conditions. The original strain produced efficient bioanodes when grown at $-0.2 \mathrm{~V} / \mathrm{SCE}$ (OCP of $-0.52 \mathrm{~V} / \mathrm{SCE}$ ); it was also able to grow at $+0.2 \mathrm{~V} / \mathrm{SCE}$ but led thus to high OCP of $0.0 \mathrm{~V} / \mathrm{SCE}$. The "electrochemically-adapted strain" that was obtained here from a month-old biofilm formed at $-0.2 \mathrm{~V} / \mathrm{SCE}$ gave in contrast low OCP whatever the polarization potential used to form the bioanode and it kept its properties during successive replications in fresh medium. In all cases, very high steady-state currents were reached, among the highest reported so far $\left(16-19 \mathrm{~A} \mathrm{~m}^{-2}\right)$. The pre-adaption of the strain leads thus to a permanent extent of the electrochemical properties of the strain. Moreover, the ability of the original strain to acquire permanent electrocatalytic properties can explain some discrepancies in the electrochemical behaviours observed in the literature, depending on the very first electrochemical treatment that the authors impose to the original strain. According to this study, it can be advised to systematically make a preliminary electrochemical adaptation of the original strain before using it to investigate $G$. sulfurreducens-bioanodes. Such a preliminary standard electrochemical adaptation will fix the electrocatalytic properties of the strain and contribute thus to a better consistency of the future various studies.

\section{Acknowledgements}

The authors gratefully thank Luc Etcheverry (LGC) for the continuous technical help and Diana Pocaznoi, Julien Riess, Claudia Cotecoy, Omar Rosas, doctoral and postdoctoral researchers in LGC for their kind contributions.

This research was part of the "Agri-Elec" (ANR-08-BioE-001) project funded by the French National Research Agency (ANR) and the AgriMip Innovation pole. 
A

(Chronoamperometry)

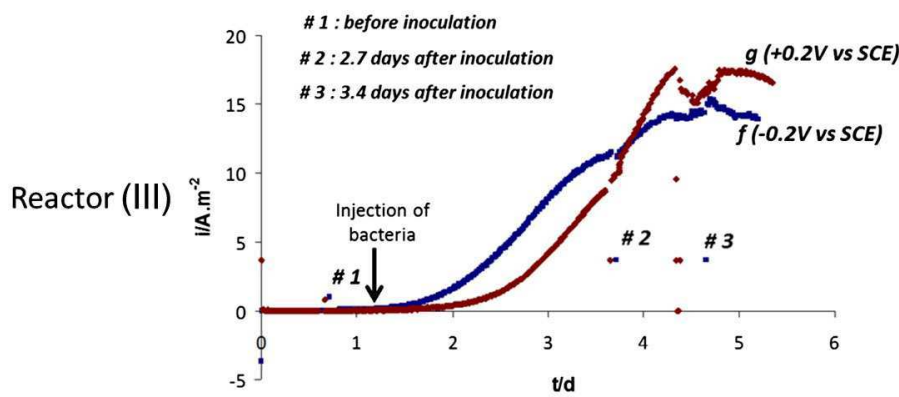

\# 1 : before inoculation

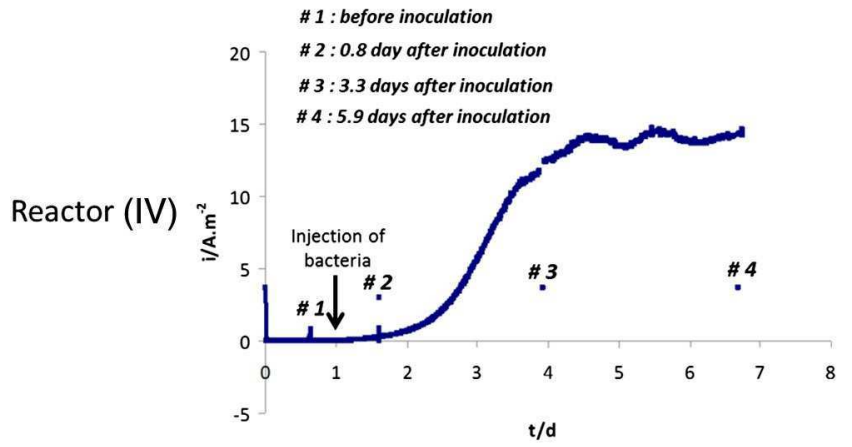

B

(Cyclic voltammetry)

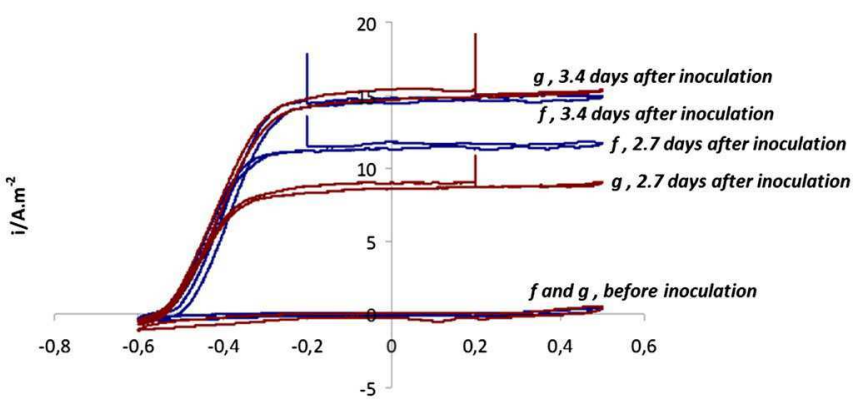

E/V vs SCE

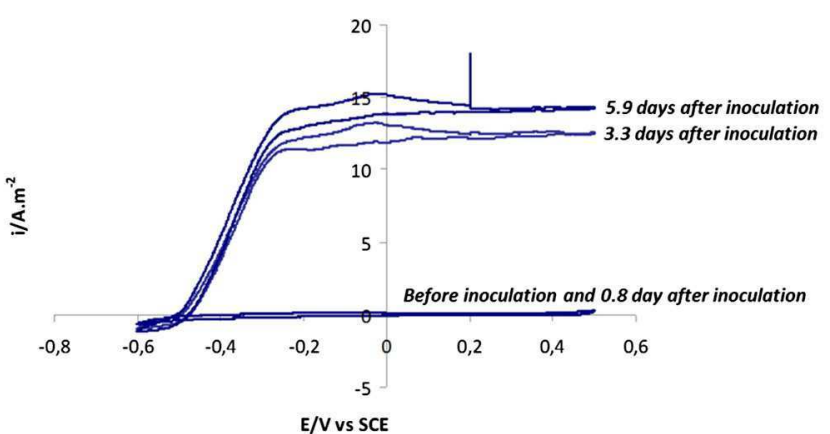

Fig. 2. Bionaodes formed with the electrochemically-adapted strain. A) Current density versus time (\# indicate the interruptions for CV recording); B) cyclic voltammetries performed at $1 \mathrm{mV} \mathrm{s}^{-1}$ during chronoamperometry. (III) Reactor with two electrodes polarized (f) at $-0.2 \mathrm{~V} / \mathrm{SCE}$ and ( $\mathrm{g}$ ) at $+0.2 \mathrm{~V} / \mathrm{SCE}$; CVs on electrodes $\mathrm{f}$ and $\mathrm{g}$ before bacteria injection, 2.7 and 3.4 days after bacteria injection. (IV) Reactor with an electrode polarized at $+0.2 \mathrm{~V} / \mathrm{SCE}$; CVs before bacteria injection, $0.8,3.3$, and 5.9 days after bacteria injection.

\section{References}

[1] D. Pant, A. Singh, G.V. Bogaert, S.I. Olsen, P.S. Nigam, L. Diels, K. Vanbroekhovena, RSC Advances 2 (2012) 1248.

[2] B.E. Logan, Nature Reviews Microbiology 7 (2009) 375

[3] D.R. Bond, D.R. Lovley, Applied and Environmental Microbiology 69 (3) (2003) 1548

[4] K.P. Katuri, P. Kavanagh, S. Rengaraj, D. Leech, Chemical Communications 46 (2010) 4758

[5] G.D. Schrott, P.S. Bonanni, L. Robuschi, A. Esteve-Nunez, J.P. Busalmen, Electrochimica Acta 56 (28) (2011) 10791

[6] E. Marsili, J.B. Rollefson, D.B. Baron, R.M. Hozalski, D.R. Bond, Applied and Environmental Microbiology 74 (23) (2008) 7329.
[7] C. Dumas, R. Basseguy, A. Bergel, Electrochimica Acta 53 (2008) 3200

[8] E. Marsili, J. Sun, D.R. Bond, Electroanalysis 22 (2009) 865.

[9] H. Richter, K. McCarthy, K.P. Nevin, J.P. Johnson, V.M. Rotello, D.R. Lovley, Langmuir 24 (2008) 4376

[10] J.P. Busalmen, A. Esteve-Nunez, J.M. Feliu, Environmental Science \& Technology $42(2008) 2445$.

[11] X. Zhu, M.D. Yates, B.E. Logan, Electrochemistry Communications 22 (2012) 116

[12] J. Wei, P. Liang, X. Cao, X. Huang, Environmental Science \& Technology 44 (2010) 3187.

[13] H. Yi, K.P. Nevin, B.-C. Kim, A.E. Frank, A. Klimes, L.M. Tender, D.R. Lovley, Biosensors and Bioelectronics 24 (2009) 349. 